\title{
SOCIAL MEDIA ANXIETY FROM THE VIEW OF JORDANIAN YOUTH: A META CONTENT ANALYSIS
}

\author{
Anwar Bani Hani ${ }^{1}$, Rohaya Talib ${ }^{2}$, Evania Yafie ${ }^{1,3}$, Areej Al_Ahmad ${ }^{4}$ \\ ${ }^{1}$ Faculty of Social Science and Humanities, Universiti Teknologi Malaysia, Skudai, 81310, Johor, \\ Malaysia \\ ${ }^{2}$ Senior Lecturer, School of Education, Universiti Teknologi, Malaysia, Johor Bahru, Malaysia. \\ ${ }^{3}$ Universitas Negeri Malang, Malang, Indonesia. \\ ${ }^{4}$ Faculty of Social Science and Humanities, The University of Jordan, Amman, Jordan. \\ Corresponding author's e-mail: anwar.hani91@yahoo.com
}

\begin{abstract}
Anxiety is contemplated to be one of the critical issues that Jordanian youth suffer from. In recent years, it was discovered from an array of studies that Jordanian youths (JY) have a big problem related to social media anxiety (SMA), which is regarded as the reason for excessive use of social media platforms (SMP). The highlighted issue here will be mentioned as that of the research problem. It crystallizes in a sharp increase in this phenomenon of "social media anxiety" by Jordanian youth, where it stressed JY's passion for using SM's platforms. Furthermore, depending on what had been observed, the massive impact of this problem on youths makes us much more interested in this study to specify the degree of influence of this issue on social media anxiety. This paper contains a massive objective, which is understanding how social media would be contributed to their health and youth lives. The paper discussed the usage of a considerable percentage of social media platforms by Jordanian youths. It has been the focal point for discussion among the specialist and educators. This paper discussed the issues concerning social media anxiety in academic and education literature, from SM's problems from the Jordanian youths' lives. The paper concludes that no effort has been made for Jordanian youth to look into social media anxiety, which has many consequences for society.
\end{abstract}

KEYWORDS: Social Media, Anxiety, Jordanian Youth, Meta Content Analysis.

\section{Introduction}

The excessive utilization of the internet and social media platforms have been associated with: behavioral addiction. Researchers became more interested in achieving a better and more in-depth perspective of this global phenomenon [1]. Social networking sites have rapidly increased in popularity over recent years. They often provide individuals with the opportunity to create private profile pages to connect with different users on the sites: through uploading contents, commenting, and messaging in various ways $[2,3]$. This event has become one of the most relevant aspects, which is a part of individuals' social circumferences, in growing adults' lives.
It is estimated that $90 \%$ of young adults in the world use social media, where most of them use two or more social media sites to visit these sites daily [4]. The growth of social media influences in the lives of emerging adults has led to increasing interest in understanding the impact of social media on their psychological adjustments. Social media could serve as a critical context through which they negotiate crucial developmental tasks, including identity development and preserving social connections [5].

Social media applications are inclusive of Facebook, Twitter, Instagram, and WhatsApp. Each year, the number of social media users increases swiftly. According to a statistic in 2019 around, it is estimated that around the globe, there will be about 2.77 billion social media users worldwide, with an approximation, up from 2.46 billion in 2017 [6].

Different age groups participate in social media differently. The number of young people (1829-year-old) users of social networking sites is rapidly increasing in the United States (USA) and other countries. There is a sharp rise in social networking sites use, among respondents between the ages of 30 to 49 (from $48 \%$ to $78 \%$ ), between ages of 50 to 64 (from $25 \%$ to $60 \%$ ), and ages of 65 years or above (from $13 \%$ to $43 \%$ ) respectively $[7,8]$.

According to [9], anxiety is an emotion characterized by tension, worried thoughts, and physical changes like increased blood pressure [10]. This, in other words, is a general definition of the concept of anxiety. Moreover, many specialists and philosophers defined it in a different meaning. Still, we will focus on this area of study based on a specific type, which is social media anxiety.

Anxiety is considered as one of the critical issues that dominate Jordanian youth life. In recent years, it was discovered from an extension of studies that Jordanian youths have a massive problem related to social media anxiety, which is regarded as the reason for excessive use of social media platforms [11]. The considerable percentage for using social media platforms by Jordanian youths has been the 
focal point for discussion among specialists and educators worldwide. Social media anxiety is a significant predictor of Jordanian youth's possibility to continue their everyday lives and their studies at a higher level. Such emphasis on using social media and social network sites could eventually contribute to developing anxious feelings among the students. Of equal importance, the investigation on social media anxiety is an ongoing concern for the youths' lives. Inarguably, it is an important area of interest within establishing the importance of the subject matter of the associated topic [12,13].

Current developments in social media anxiety have heightened the need for attentiveness, meaningful understanding, and the relationship between social media and anxiety $[14,15]$. In the current synopsis of literature apprised, investigators examine the effects of social media anxiety on youths' lives. Some components found to influence social media anxiety have been explored in several studies by $[16,17]$.

By highlighting the inadequacies of previous studies [18], the researchers found a sharp increase in social media anxiety by Jordanian youth due to the excessive use of social media platforms. Moreover, the researchers have not been interested in this issue as enough. In the current study focusing on the knowledge gap for social media anxiety, it was found that the impact of social media anxiety on Jordanian youth still is not investigated well and not clear by past researchers [19].

A significant problem with this type of anxiety (social media anxiety) is a sharp increase in the highlighted phenomenon. By deciphering previous studies' inadequacies, researchers have not treated social media anxiety in many different details and notions. Incidentally, focusing on a knowledge gap in the study field, what is unclear is the impact of social media anxiety on Jordanian youths, precisely on Jordanian high school students.

Along with this, there were limited previous studies that have investigated the social media anxiety scale. Simultaneously, this study examines the relationship between social media and some mental health problems, like anxiety. Thus, it has found a correlation between them [20,21,22]. Additionally, by using the literature review, meta content analysis, this study collected the best homogenous dimensions to construct the social media anxiety scale [23].

In Jordan, a limited study has evaluated the prevalence, the risk factors, and the predictors of social media anxiety among Jordanian youth. The current study is considered the first in this area, and it would help fill in the gap on the knowledge about this problem from the Jordanians perspectives. This study will also contribute to uncovering social media anxiety among Jordanian youth who are still schooling from age (17-18).

According to counter global stats, Figure 1 highlighted that the Social Media Stats in Jordan June 2020. Facebook $88.69 \%$, YouTube $8.83 \%$, Twitter $0.88 \%$, Instagram $0.44 \%$ and LinkedIn $0.07 \%$ [24].

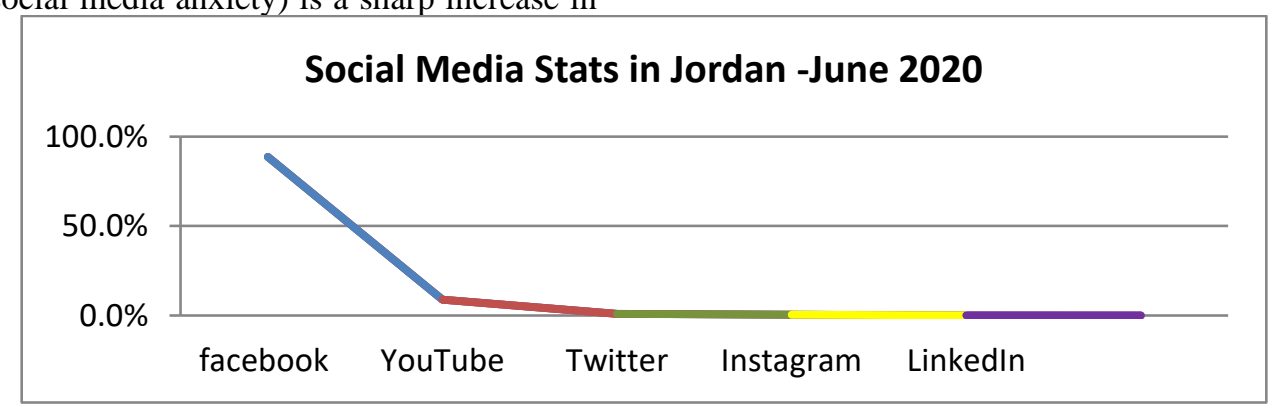

Figure 1 Social Media Stats in Jordan - June 2020

\begin{tabular}{|l|c|c|c|}
\hline \multicolumn{1}{|c|}{ Social Media Platforms (SMP) } & Number of Users & $\begin{array}{c}\text { The Compared with total } \\
\text { Population\% }\end{array}$ \\
\hline \multicolumn{2}{|c|}{ TOTAL POPULATION IS 10.15 MILLION } \\
\hline FACEBOOK & 5 million & $69 \%$ \\
\hline INSTAGRAM & 2.10 million & $29 \%$ \\
\hline SNAP CHAT & 2.15 million & $30 \%$ \\
\hline TWITTER & 743.5 thousand & $10 \%$ \\
\hline LINKEDIN & 910.0 thousand & $15 \%$ & \multirow{2}{*}{} \\
\hline
\end{tabular}

Table 1 The Number and Compared of the Jordanian Users with Total Population

Social Media has turned into a state of addiction, according to the description of citizens on this phenomenon. Plus, it revealed that Jordanians' interest and passion for social networks (Facebook, Twitter, Instagram, Snap chat, etc.) had profoundly increased $[25,26]$. Table 1 below shows the number 
and the comparison of the Jordanian users of the total population [27,28], which mentioned the social media platforms, numbers of users, compared with the total population and active social media users in millions.

According to local official figures [28], the number of Internet users in Jordan is about 6.78 million users. Based on the global ratio, the number of users of various national networks is about 7.2 million users. Based on the reporting of potential advertising reach of selected social media platforms: the total number of active social media users is 5.70 million; the social media user compared to the total population is $56 \%$. Change in social media users numbers (April 2019 to Jan 2020) $(+7.4 \%)(+394$ thousand). The percentage of active social media users accessing via mobile is $100 \%$. There were 5.70 million social media users in Jordan in January 2020. The number of social media users in Jordan increased by 394 thousand $(+7.4 \%)$ between April and January 2020. Social media assimilation in Jordan stood at $56 \%$ in January 2020 [27,28]. The highlighted issue mentioned here is that of the research problem, where it crystallizes in a sharp increase in this phenomenon of social media anxiety, by Jordanian youth, according to (Bioresearch Centre), where it stressed the passion of Jordanian youth on using the platforms of social media.

Everything has two sides, positive and negative. To continue talking about social media anxiety, which is also related to the topic of excessive use in mobile phones, some studies, like [29], found that most people aim to use social media, which is getting rid of spare time. Social media anxiety affects the economic side through communication platforms such as Facebook, Twitter, and others. Also, it causes a weakness in the direct social relationship among family, relatives, and friends. The last cause is a supplementary to negative repercussions on children's mentality [30]. Thus, the above reasons support the concept of the development and validation of the social media anxiety scale for Jordanian high school students and the comprehension of the effect of social media anxiety on Jordanian youth lives. Hence, to solve the current problem, this study aims to develop and validate the social media anxiety scale for Jordanian high school students.

From the synthesis of the information of prior reviewed literature studies, there were few researchers that were interested in knowing the relationship between social media use and anxiety disorder. This mentioned part would enlighten some of the unraveling's of these studies, which would be a means of a supportive framework and the facilitation of this study. A study, where a sample of adolescents and adults from a Norwegian community, who endorsed the increase in symptoms and signs of anxiety, particularly in this category, and, as a result, revealed the addiction notion, arisen from the use of social media [31].

Another study, on a group of university students in the United States (USA), where one gender group sample was selected, only for females. This study confirmed the increase of anxiety due to addiction and social media misuse, significantly; " Facebook" platform, which is considered the most popular networking benchmark, between social networking [32,33]. Inferring from the statistics from (2010-2018) [34], the number of social media users reached a peak at 2.375 billion. Another factor influencing the delay in responding to some requests for friendship is anxiety [35]. On the other hand, other studies have failed to conduct gate new findings in sequence; to explore and discover the failures in determining the relationship between social media and anxiety level. This may be the result of this study, which has been applied to a small sample of young people or another criterion [36].

In particular, to develop and validate various scales, several studies have successfully been conducted using different techniques. These studies strongly correlated with the topic of the current study, social media anxiety $[31,37,38]$. Conversely, these studies had a moderate correlation [39,40]. Moreover, some of the previous studies claimed no relationship between social media and anxiety [41,42]. All these studies, irrespective of the techniques used, have successfully developed a valid and reliable measure for assessing various aspects of evaluation or achievements by examining the scale items' psychometric properties, using rigorous statistical techniques. As far as we know, no previous research has investigated the construct and development of a scale to measure this kind of anxiety; social media anxiety, which is considered unique and deserves to be studied, and it had a significant impact on the ability to measure it. This contribution is considered mostly motivated to fill the gap of this study [15].

\section{Materials and Methods}

After reviewing all the reasons and figures for development and validation of the social media anxiety scale study, it is investigated by the social media anxiety phenomenon that meta-content analysis and literature review will be used based on 8 dimensions which are introvert, emotional stability, shyness, hedonic, panic, avoidance, worry, and fear. Besides, the respondents will be Jordanian high school students. Moreover, this study's scope will be the "North Zone" (Kasbah Irbid district). These reasons were supported to investigated in this study, for the conception of all the sides and interests of this phenomenon, simultaneously, to solve the problems that increased with it $[27,28,43,44,45]$ 
Table 2.3 The Characteristics of Meta-Content Analysis

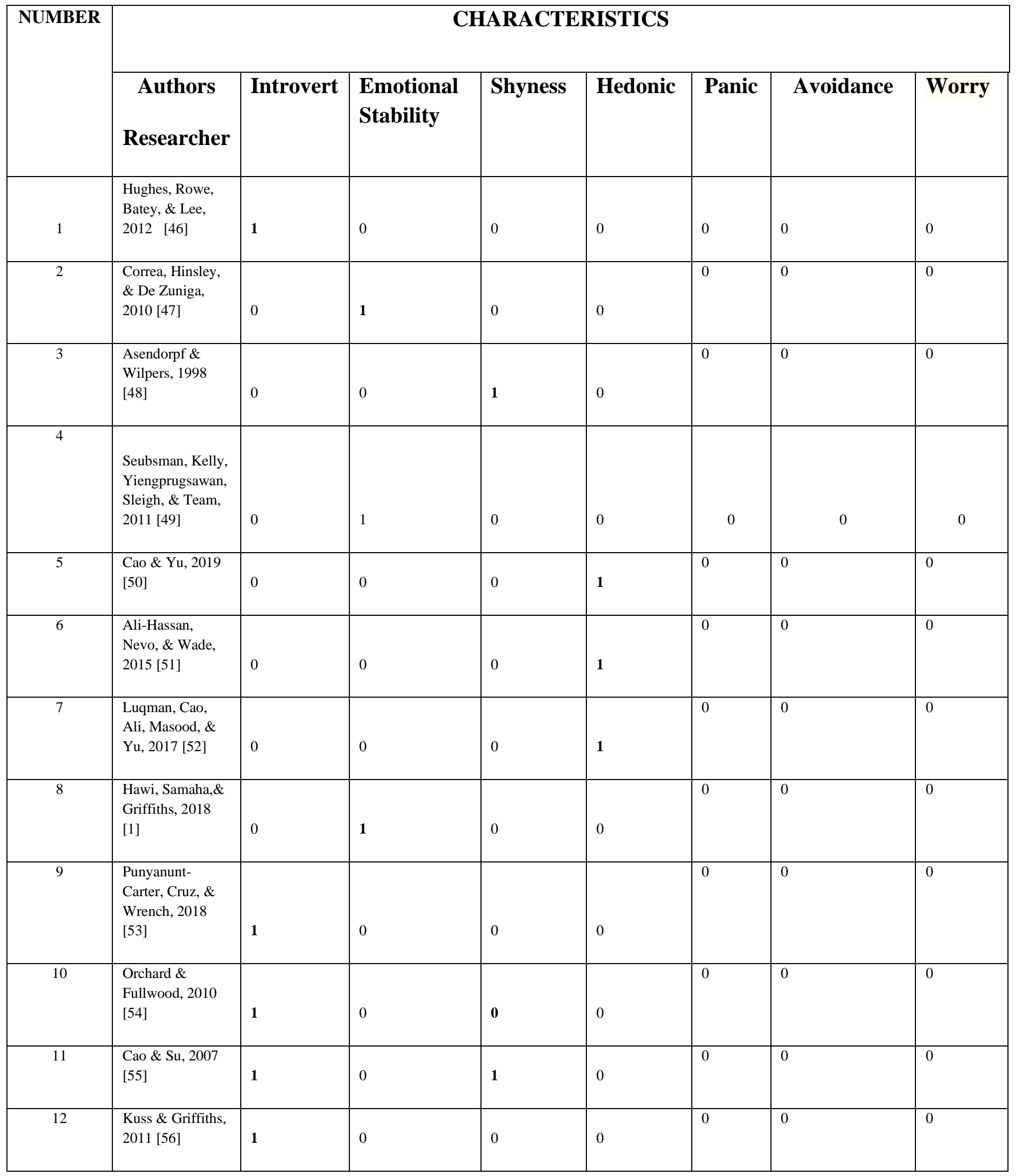


IT in Industry, Vol. 9, No.1, 2021

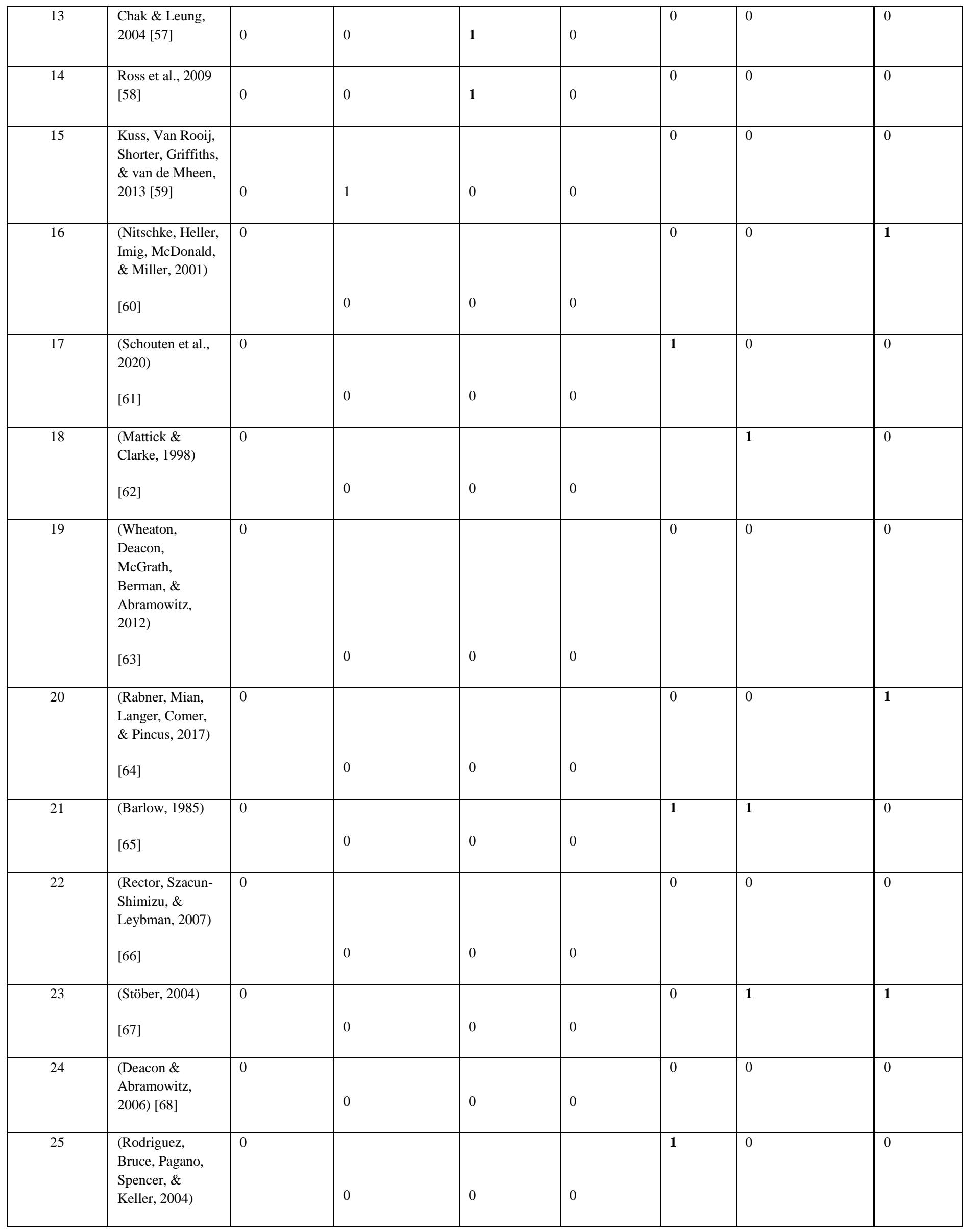




\begin{tabular}{|c|c|c|c|c|c|c|c|c|}
\hline & $\begin{array}{l}\text { [69] } \\
\end{array}$ & & & & & & & \\
\hline 26 & $\begin{array}{l}\text { (Chorpita, 2002) } \\
{[70]}\end{array}$ & 0 & 0 & 0 & 0 & 1 & 0 & 0 \\
\hline 27 & $\begin{array}{l}\text { (Masia-Warner et } \\
\text { al., 2003) [71] }\end{array}$ & 0 & 0 & 0 & 0 & 0 & 1 & 0 \\
\hline 28 & $\begin{array}{l}\text { (Shear, Bjelland, } \\
\text { Beesdo, Gloster, } \\
\& \text { Wittchen, } \\
\text { 2007) } \\
{[72]}\end{array}$ & 0 & 0 & 0 & 0 & 1 & 1 & 0 \\
\hline 29 & $\begin{array}{l}\text { (Collimore, } \\
\text { McCabe, } \\
\text { Carleton, \& } \\
\text { Asmundson, } \\
\text { 2008) } \\
{[73]}\end{array}$ & 0 & 0 & 0 & 0 & 0 & 1 & 0 \\
\hline 30 & $\begin{array}{l}\text { (Lehrer \& } \\
\text { Woolfolk, 1982) } \\
\text { [74] }\end{array}$ & 0 & 0 & 0 & 0 & 0 & 1 & 1 \\
\hline 31 & $\begin{array}{l}\text { (Wenzel, Haugen, } \\
\text { Jackson, \& } \\
\text { Brendle, 2005) } \\
\text { [75] }\end{array}$ & 0 & 0 & 0 & 0 & 1 & 0 & 0 \\
\hline 32 & $\begin{array}{l}\text { (Langford, 1937) } \\
\text { [76] }\end{array}$ & 0 & 0 & 1 & 0 & 0 & 0 & 0 \\
\hline 33 & $\begin{array}{l}\text { (Shin \& } \\
\text { Liberzon, 2010) } \\
{[77]}\end{array}$ & 0 & 0 & 0 & 0 & 1 & 0 & 0 \\
\hline 34 & $\begin{array}{l}\text { (McNaughton \& } \\
\text { Corr, 2004) } \\
{[78]}\end{array}$ & 0 & 0 & 0 & 0 & 1 & 0 & 0 \\
\hline 35 & $\begin{array}{l}\text { (Reiss, 1987) } \\
\text { [79] }\end{array}$ & 0 & 0 & 0 & 0 & 0 & 1 & 1 \\
\hline 36 & $\begin{array}{l}\text { (McWilliams, } \\
\text { Stewart, \& } \\
\text { MacPherson, } \\
\text { 2000) [80] }\end{array}$ & 0 & 0 & 0 & 0 & 0 & 0 & 0 \\
\hline 37 & $\begin{array}{l}\text { (Gardenswartz \& } \\
\text { Craske, 2001) } \\
{[81]}\end{array}$ & 0 & 0 & 0 & 0 & 1 & 0 & 0 \\
\hline 38 & $\begin{array}{l}\text { (Lasser et al., } \\
\text { 2000) [82] }\end{array}$ & 0 & 0 & 0 & 0 & 1 & 0 & 0 \\
\hline 39 & $\begin{array}{l}\text { (Kashdan, 2004) } \\
\text { [83] }\end{array}$ & 0 & 0 & 0 & 1 & 0 & 0 & 0 \\
\hline
\end{tabular}




\begin{tabular}{|l|l|l|l|l|l|l|l|l|}
\hline 40 & $\begin{array}{l}\text { (Tamir, Chiu, \& } \\
\text { Gross, 2007) [84] }\end{array}$ & 0 & 0 & 0 & 1 & 0 & 1 & 1 \\
\hline 41 & $\begin{array}{l}\text { (Shi, Li, Zhang, } \\
\& \text { Zhang, 2017) } \\
{[85]}\end{array}$ & 0 & 1 & 0 & 1 & 0 & 0 & 1 \\
\hline 42 & $\begin{array}{l}\text { (Arnold \& } \\
\text { Reynolds, 2012) } \\
{[86]}\end{array}$ & 0 & 0 & 0 & 1 & 0 & 1 & 0 \\
\hline
\end{tabular}

\section{Conceptual Definition (CD)}

From the dimensions selected, the researcher formulated the conceptual definition of Social Media Anxiety, which shown in Table 2.

Table 2 Conceptual Definition

\section{Dimensional of social media anxiety (SMA)}

\section{CONCEPTUAL DEFINITION}

A conceptual definition is a definition outlining the basic principles underlying a term. It involves thinking carefully, observing directly, consulting with others, and, reading what others have said. Conveys the general meaning of the concept, such as might be found in a dictionary. It can reflect the framework used in the study.

In this study, after going through the meta- content analysis Table 2 theoretical and conceptual paradigm, the study was generated of conceptual definition from the collection of the dimensions and their characteristics, that collected from the meta- content analysis. Where for this study, a conceptual definition was defined as some explanation of the author's intended meaning through the use of social media anxiety or some abstract discussion of how one might measure social media anxiety.

Social Media Anxiety (SMA), is defined as a feeling of stress or discomfort related to the use of social media, often due to an intense focus on the level of popularity someone thinks they have achieved or failed to achieve on platforms like Facebook and Twitter [87]. Moreover, this study will investigate the significant and common platforms which use in Jordan mainly. These platforms are Facebook, Instagram, Snap chat, Twitter, respectively. Besides, these platforms took the highest rank in use by Jordanian between all of the social media platforms, which was the main cause to investigate it. According to this study, social media anxiety will carry a new definition depending on the group of dimensions, and its characteristics that extracted depending on the meta content analysis from the literature review; introvert, emotional stability, shyness, hedonic, panic, avoidance, worry, and fear.

An introvert, is collected from some characteristics, shy, quiet, and prefers to spend time alone, in other words when someone prefers calm, minimally stimulating environments [88].

Emotional stability, the state of being firmly fixed or not likely to move or change relating to the emotions or having and expressing strong feelings, refers to the ability of a person to stay stable and healthy [89].

Shyness, is the feeling of apprehension, lack of comfort, or awkwardness, especially when a person is around other people [57].

Hedonic refers to characterized by pleasure or anything related to leisure. It is a way of life-based on or suggesting the principles of hedonism and emotional feelings such as love, hate, fear, joy [50]. 
Panic, is a sudden sensation of fear, which is so strong as to dominate or prevent reason and logical thinking, replacing it with overwhelming feelings of anxiety. Besides, it is an anxiety disorder where you regularly have sudden attacks of panic or fear [90].

Avoidance, escape coping is a maladaptive coping mechanism characterized by the effort to avoid dealing with a stressor. It refers to behaviours that attempt to protect oneself from psychological damage [91,92].

Worry, refers to the thoughts, images, emotions, and actions of a negative nature in a repetitive, uncontrollable manner that results from a proactive cognitive risk analysis made to avoid or solve anticipated potential threats and their potential consequences [93].

Fear, is an emotion induced by perceived danger or threat, which causes physiological changes and ultimately behavioural changes, such as fleeing, hiding, or freezing from perceived traumatic events. Fear alerts us to the presence of danger or the threat of harm, whether that danger is physical or psychological [94].

\section{Operational Definition (OD)}

Table 3 consists of operational definitions of each dimension selected, which will be used to construct the item for social media anxiety scale.

Table 3 Operational Definition

\section{OPERATIONAL DEFINITION}

- Having empirical referents, to be able to count /measure the gathered info through senses.

- Measure observable /visible / recognizable /detectable characteristics of behaviours .

- Gives you the procedures or operations, required to measure the concept.

- It supplies information, so you know how the data will be collected.

\begin{tabular}{|c|c|}
\hline 1-An introvert & $\begin{array}{l}\text { - } \quad \text { Don't enjoy in the large social events. } \\
\text { - } \quad \text { Spending a lot of time lonely. } \\
\text { - } \quad \text { Never excitement to meet others face to face . } \\
\text { - } \quad \text { Doing my work alone rather than do it with the group. } \\
\text { - } \quad \text { Prefer to get on a few close friends rather than a large group of friends } \\
\text { - } \quad \text { Sometimes feeling happy, sometimes depressed, without any apparent reason. } \\
\text { - } \quad \text { Have frequent ups and downs in mood, either with or without apparent cause. } \\
\text { - } \quad \text { Feeling unhappy if you were prevented from making numerous social contacts. }\end{array}$ \\
\hline 2-Emotional stability & $\begin{array}{l}\text { - } \quad \text { Do not get irritated easily. } \\
\text { - } \quad \text { Never get stressed out easily. } \\
\text { - } \quad \text { Do not ever get upset easily. } \\
\text { - } \quad \text { Have not frequent mood swings. } \\
\text { - } \quad \text { Do not worried about things. } \\
\text { - } \quad \text { I am relaxed most of the time. }\end{array}$ \\
\hline 3-Shyness & $\begin{array}{l}\text { - } \quad \text { Feeling tense when I'm with people I don't know well. } \\
\text { - } \quad \text { During conversations with new acquaintances, I worry about saying something } \\
\text { - } \quad \text { Fumb. } \\
\text { - } \quad \text { Seeling socially somewhat awkward. } \\
\text { - } \quad \text { Painfully self-conscious when I am around strangers. } \\
\text { - } \quad \text { Worrying about how well I will get along with new acquaintances. } \\
\text { - } \quad \text { Tending to be very quiet anywhere. } \\
\text { - } \quad \text { Talking more in a small group rather than the big one. }\end{array}$ \\
\hline
\end{tabular}




\begin{tabular}{|c|c|}
\hline 4-Hedonic & $\begin{array}{l}\text { - } \quad \text { Enjoy my favourite television or radio program. } \\
\text { - } \quad \text { Enjoy being with my family or close friend. } \\
\text { - } \quad \text { Find pleasure in my hobbies and pastimes. } \\
\text { - } \quad \text { Get pleasure from helping others. } \\
\text { - } \quad \text { Feel pleasure when I receive praise from other. } \\
\text { - } \quad \text { Need for tryout emotional experiences. } \\
\text { - } \quad \text { Passing time on leisure activities. }\end{array}$ \\
\hline 5-Panic & $\begin{array}{l}\text { - Suddenly, feel as if i can't breathe when there is no reason for this. } \\
\text { - Suddenly, start to tremble or shake when there is no reason for this. } \\
\text { - Worrying that suddenly get a scared feeling when there is nothing to be afraid } \\
\text { - } \text { of. } \\
\text { - Shen i have a problem i get a strange feeling in my stomach. } \\
\text { - Feeling scared if i have to try new things. } \\
\text { - Feeling afraid of being in crowded groups. }\end{array}$ \\
\hline 6-Avoidance & $\begin{array}{l}\text { - } \quad \text { Convincing myself that it's not all bad. } \\
\text { - } \quad \text { Putting thoughts that related to my problems out of my mind. } \\
\text { - } \quad \text { Never try to think about the important things like studying or exams. } \\
\text { - } \quad \text { Turning to other activities for diversion. } \\
\text { - } \quad \text { Persuading myself that I don't care about any essential things. } \\
\text { - Going anywhere to avoid thinking about the necessary activities that i must do } \\
\text { it. } \\
\text { Making a conscious effort to think about something else rather than the } \\
\text { important one. }\end{array}$ \\
\hline 7-Worry & $\begin{array}{l}\text { - } \\
\text { - } \quad \text { Worryious that others will be disappointed in my plans. } \\
\text { - } \quad \text { Having self-doubts about everything. } \\
\text { - } \quad \text { Anxious if i may never do as well in tasks as i could. } \\
\text { - } \quad \text { Worrying about what other people think about me. } \\
\text { - } \quad \text { Concern about my plans poorly. } \\
\text { - } \quad \text { Often, worrying about something terrible happening to me. }\end{array}$ \\
\hline 8-Fear & $\begin{array}{l}\text { - } \quad \text { Fear that my friends have accounts more than mine. } \\
\text { - } \text { Always scared of chatting with others. } \\
\text { - } \text { Fear the others have more friends more than mine. } \\
\text { - } \quad \text { Afraid if i feel the others have more experiences than me. } \\
\text { - } \text { Aware of knowing any strange persons. } \\
\text { - } \quad \text { Afraid that others will not approve of me. } \\
\text { - }\end{array}$ \\
\hline
\end{tabular}

\section{Results and discussion}

\section{Discussion of the Social Media Anxiety Terminologies}

\section{i. Social Media Anxiety (SMA)}

Social Media Anxiety is defined as a feeling of stress or discomfort related to social media use, which often is due to an intense focus on the level of popularity, where someone thinks they have succeeded or failed to achieve on platforms like Facebook and Twitter [46]. In this study, this definition (SMA) took an un-usual and a new meaning, it is a valuable notion that is defined, consisting of a group of characteristics that describe or express the terms; " introvert, emotional stability, shyness, hedonic, panic, avoidance, worry, and fear.

- According to this study, social media anxiety, defined depending on the group of dimensions and its characteristics. Hedonic is characterized by pleasure or anything related to leisure [50]. In this study, it is a mix of expressions or action, where, enjoy my favorite television or radio program, enjoy being with my family or close friend, 
find pleasure in my hobbies and pastimes, get pleasure from helping others, feel joy when I receive praise from other, need for tryout emotional experiences, and passing the time on leisure activities.

- Introvert is considered one social media anxiety dimension where someone prefers calm and minimally stimulating environments [49]. In this study, it is defined as a mix of expressions or action, where, don't enjoy in the large social events, spending a lot of time lonely, never excitement to meet others face to face, doing my work alone rather than do it with the group, prefer to get on a few close friends rather than a large group of friends, sometimes feeling happy, sometimes depressed, without any apparent reason, have frequent ups and downs in mood, either with or without apparent cause, and feeling unhappy if you were prevented from making numerous social contacts.

- Emotional stability refers to a person's ability to remain stable and balanced [50]. In this study, the defined was a mix of expressions or action, where do not get irritated quickly, never get stressed out easily, do not ever get upset quickly., have not frequent mood swings, do not worried about things, do not much more anxious than most people, and I am relaxed most of the time.

- Shyness is the feeling of apprehension, lack of comfort, or awkwardness, especially when a person is around other people [54]. In this study, the definition is a mix of expressions or action, where, feeling tense when I'm with people I don't know well, during conversations with new acquaintances, I worry about saying something dumb, feeling socially somewhat awkward, sensation uncomfortable at parties and other social gatherings, painfully self-conscious when I am around strangers, worrying about how well I will get along with new acquaintances, tending to be very quiet anywhere, and talking more in a small group rather than the big one.

- Panic is a sudden sensation of fear, which is so strong as to dominate or prevent reason and logical thinking, replacing it with overwhelming anxiety feelings [90]. In this study, the definition is a mix of expressions or action, where, suddenly, feel as if i can't breathe when there is no reason for this, suddenly, start to tremble or shake when there is no reason for this, worrying that suddenly get a scared feeling when there is nothing to be afraid of, when $i$ have a problem $i$ get a strange feeling in my stomach, suddenly, the heart starts to beat too quickly for no reason, feeling scared if $i$ have to try new things and feeling afraid of being in crowded groups.

- Avoidance, escape coping is a maladaptive coping mechanism characterized by avoiding dealing with a stressor [91]. In this study, the definition is a mix of expressions or action, where, convincing myself that it's not all bad, putting thoughts that related to my problems out of my mind, never try to think about the important things like studying or exams, turning to other activities for diversion, persuading myself that I don't care about any essential things, going anywhere to avoid thinking about the necessary activities that $\mathrm{i}$ must do it, and making a conscious effort to think about something else rather than the important one.

- Worry refers to the thoughts, images, emotions, and actions of a negative nature in a repetitive, uncontrollable manner that results from a proactive cognitive risk analysis made to avoid or solve anticipated potential threats and their possible consequences [93]. In this study, the definition is a mix of expressions or action, where, anxious that others will be disappointed in my plans, worrying about reaching my goals or dreams, having selfdoubts about everything, anxious if $\mathrm{i}$ may never do as well in tasks as i could, worrying about what other people think about me, getting nervous when things do not go the right way for me, concern about my plans poorly, and often, worrying about something terrible happening to me.

- Fear is an emotion induced by perceived danger or threat, which causes physiological changes and ultimately behavioral changes, such as fleeing, hiding, or freezing from perceived traumatic events [94]. In this study, the definition is a mix of expressions or action, where, fear that my friends have accounts more than mine, always scared of chatting with others, fear the others have more friends more than mine, get anxious when i don't know what my friends practice, afraid if $i$ feel the others have more experiences than me, aware of knowing any strange persons, afraid that others will not 
approve of me, and afraid that people will find fault with me.

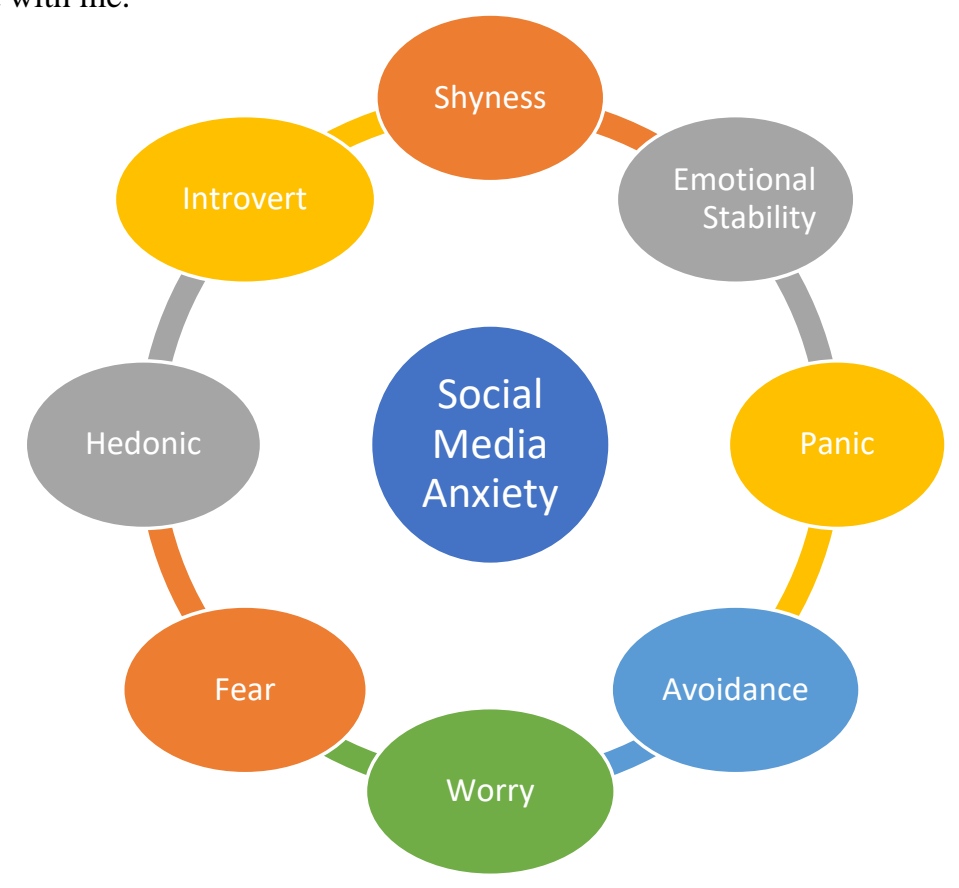

Figure 2 The Characteristics of Social Media Anxiety (SMA).

\section{Conclusion}

The paper presented a novelty definition for this important topic, which includes many characteristics; it's social media anxiety to measure students' anxiety levels. Social media anxiety features and characteristics make it efficient and significant to develop social media anxiety scale for Jordanian youth. It could be used as a supplement and support in secondary schools to measure and know the levels of severity of this problem between students without any efforts by them. Therefore, it was suggested that Jordanian high school students have to undergo this scale before starting them because it is a critical stage to transfer them to pursue their higher education. Also, they need this scale, which is very important to them for knowing who suffers from this problem and treating it before growing it.

\section{Acknowledgements}

We are very grateful to experts for their appropriate and constructive suggestions to improve this article.

\section{References}

[1] Hawi, N., \& Samaha, M. (2019). Identifying commonalities and differences in personality characteristics of Internet and social media addiction profiles: traits, self-esteem, and selfconstrual. Behaviour \& Information Technology, 38(2), 110-119.

[2] Boyd, D. M., \& Ellison, N. B. (2007). Social network sites: Definition, history, and scholarship. Journal of computer-mediated Communication, 13(1), 210-230.

[3] Joinson, A. N. (2008). Looking at, looking up or keeping up with people?: motives and use of facebook. Paper presented at the Proceedings of the SIGCHI conference on Human Factors in Computing Systems.

[4] Perrin, A. (2015). Social media usage: 20052015.

[5] Moreno, M. A., \& Whitehill, J. M. (2014). Influence of social media on alcohol use in adolescents and young adults. Alcohol research: current reviews, 36(1), 91.

[6] Statista. (2018). "Number of social media users worldwide 2010-2021 | Statista".

[7] Brenner, J., \& Smith, A. (2013). 72\% of online adults are social networking site users. Washington, DC: Pew Internet \& American Life Project.

[8] Madden, M., \& Zickuhr, K. (2011). 65\% of online adults use social networking sites. Pew Internet \& American Life Project, 1, 14. 
[9] Association. (2018). APA guidelines for psychological practice with boys and men. APA guidelines for psychological practice with boys and men.

[10] Corsini, R. J., \& Ozaki, B. D. (1994). Encyclopedia of psychology (Vol. 1): Wiley New York.

[11] Ismayilova, L., Hmoud, O., Alkhasawneh, E., Shaw, S., \& El-Bassel, N. (2013). Depressive symptoms among Jordanian youth: results of a national survey. Community mental health journal, 49(1), 133-140.

[12] Ahn, J. (2011). The effect of social network sites on adolescents' social and academic development: Current theories and controversies. Journal of the American Society for information Science and Technology, 62(8), 1435-1445.

[13] O'Keeffe, G. S., \& Clarke-Pearson, K. (2011). The impact of social media on children, adolescents, and families. Pediatrics, 127(4), 800-804.

[14] Vannucci, A., Flannery, K. M., \& Ohannessian, C. M. (2017). Social media use and anxiety in emerging adults. Journal of affective disorders, 207, 163-166.

[15] Woods, H. C., \& Scott, H. (2016). \# Sleepyteens: Social media use in adolescence is associated with poor sleep quality, anxiety, depression and low self-esteem. Journal of adolescence, 51, 41-49.

[16] Kuppuswamy, S., \& Narayan, P. S. (2010). The impact of social networking websites on the education of youth. International journal of virtual communities and social networking (IJVCSN), 2(1), 67-79.

[17] Shabir, G., Hameed, Y. M. Y., Safdar, G., \& Gilani, S. (2014). The Impact of Social Media on Youth: A Case Study of Bahawalpur City. Asian Journal of Social Sciences \& Humanities, 3(4), 132-151.

[18] Atoum, A., \& Al-Hattab, L. (2015). Internet addiction and its relation to psychosocial adaptation among Jordanian high basic stage students. Journal of Psychology and Behavioral Science, 3(1), 96-104.

[19] Malak, M. Z., Khalifeh, A. H., \& Shuhaiber, A. H. (2017). Prevalence of Internet Addiction and associated risk factors in Jordanian school students. Computers in Human Behavior, 70, 556-563.

[20] Lin, L. Y., Sidani, J. E., Shensa, A., Radovic, A., Miller, E., Colditz, J. B., . . . Primack, B. A. (2016). Association between social media use and depression among US young adults. Depression and anxiety, 33(4), 323-331.

[21] Naslund, J., Aschbrenner, K., Marsch, L., \& Bartels, S. (2016). The future of mental health care: peer-to-peer support and social media.
Epidemiology and psychiatric sciences, 25(2), 113-122.

[22] Wongkoblap, A., Vadillo, M. A., \& Curcin, V. (2017). Researching mental health disorders in the era of social media: systematic review. Journal of medical Internet research, 19(6), e228.

[23] Doré, I., O'Loughlin, J. L., Beauchamp, G., Martineau, M., \& Fournier, L. (2016). Volume and social context of physical activity in association with mental health, anxiety and depression among youth. Preventive Medicine, 91, 344-350.

[24] Statista. (2016). Number of smartphone users worldwide from 2014 to 2020 (in billions).

[25] Al-Madina, N. (2016). Jordan: Social media "addiction" leads its users to isolation.

[26] Jin, H. (2015). Understanding media's extensions Commemoration of the 50th anniversary of the publication of Marshall McLuhan's Understanding media: the extensions of man. Critical Arts, 29(6), 818826.

[27] Kemp, S. (2019a). Digital 2019: Global digital overview. Retrieved from Datareportal: https://datareportal. com/reports/digital-2019global-digital-overview.

[28] Social, W. A. (2020). Digital 2020 Global Digital Overview. Erişim Tarihi, 18(03), 2020.

[29] Farfouri, Y. (2016). Social networking site (Facebook) and its impact on members of society: from addiction to social isolation.

[30] Silver, L., Smith, A., Johnson, C., Taylor, K., Jiang, J., Anderson, M., \& Rainie, L. (2019). Mobile connectivity in emerging economies. Pew Research Center, 7.

[31] Andreassen, C. S., Billieux, J., Griffiths, M. D., Kuss, D. J., Demetrovics, Z., Mazzoni, E., \& Pallesen, S. (2016). The relationship between addictive use of social media and video games and symptoms of psychiatric disorders: A large-scale cross-sectional study. Psychology of Addictive Behaviors, 30(2), 252.

[32] Ahmed, I., \& Qazi, T. F. (2011). A look out for academic impacts of Social networking sites (SNSs): A student based perspective. African Journal of Business Management, 5(12), 50225031.

[33] Hurt, N. E., Moss, G. S., Bradley, C. L., Larson, L. R., Lovelace, M., Prevost, L. B., . . . Camus, M. S. (2012). The" Facebook" Effect: College Students' Perceptions of Online Discussions in the Age of Social Networking. International Journal for the Scholarship of Teaching and Learning, 6(2), n2.

[34] Statista. (2015). Number of social network users worldwide from 2010 to 2018 (in billions).

[35] Campisi, J., Bynog, P., McGehee, H., Oakland, J. C., Quirk, S., Taga, C., \& Taylor, M. (2012). 
Facebook, stress, and incidence of upper respiratory infection in undergraduate college students. Cyberpsychology, Behavior, and Social Networking, 15(12), 675-681.

[36] Kross, E., Verduyn, P., Demiralp, E., Park, J., Lee, D. S., Lin, N., . . . Ybarra, O. (2013). Facebook use predicts declines in subjective well-being in young adults. PloS one, 8(8), e69841.

[37] Appel, M. a., \& Gnambs, T. (2019). Shyness and social media use: A meta-analytic summary of moderating and mediating effects. Computers in Human Behavior, 98, 294-301.

[38] Aydogan, D., \& Buyukyilmaz, O. (2017). The Effect of Social Media Usage on Students' Stress and Anxiety: A Research in Karabuk University Faculty of Business. International Journal of Multidisciplinary Thought, 6(1), 253-260.

[39] Esmaeili Rad, M., \& Ahmadi, F. (2018). A new method to measure and decrease the online social networking addiction. Asia-Pacific Psychiatry, 10(4), e12330.

[40] Iranmanesh, M., Foroughi, B., Nikbin, D., \& Hyun, S. S. (2019). Shyness, self-esteem, and loneliness as causes of FA: The moderating effect of low self-control. Current Psychology, $1-12$.

[41] Muench, F., Hayes, M., Kuerbis, A., \& Shao, S. (2015). The independent relationship between trouble controlling Facebook use, time spent on the site and distress. Journal of behavioral addictions, 4(3), 163-169.

[42] Zaffar, M., Mahmood, S., Saleem, M., \& Zakaria, E. (2015). Facebook addiction: Relation with depression, anxiety, loneliness and academic performance of Pakistani students. Science International (Lahore), 27(3), 2469-2475.

[43] Edwards, S. M., \& Lee, W. N. (2000). Adolescents' use of traditional media and the Internet. Journal of Advertising Research.

[44] Sharif, D. A. Q. (2015). Facebook in the Arab World: a scientific study of the phenomenon of virtual organizations. Magazine of Political Studies and International Relations, 276 (1741), 1-44.

[45] Tahseen. (2014). The role of social media in fulfilling the needs of Jordanian university youth. Jordan Journal of Social Sciences, , 7 (2).

[46] Hughes, D. J., Rowe, M., Batey, M., \& Lee, A. (2012). A tale of two sites: Twitter vs. Facebook and the personality predictors of social media usage. Computers in Human Behavior, 28(2), 561-569.

[47] Correa, T., Hinsley, A. W., \& De Zuniga, H. G. (2010). Who interacts on the Web?: The intersection of users' personality and social media use. Computers in Human Behavior, 26(2), 247-253.

[48] Asendorpf, J. B., \& Wilpers, S. (1998). Personality effects on social relationships. Journal of personality and social psychology, 74(6), 1531.

[49] Seubsman, S.-a., Kelly, M. J., Yiengprugsawan, V., Sleigh, A. C., \& Team, T. C. S. (2011). Gender, socioeconomic status, and self-rated health in a transitional middle-income setting: evidence from Thailand. Asia Pacific Journal of Public Health, 23(5), 754-765.

[50] Cao, X., \& Yu, L. (2019). Exploring the influence of excessive social media use at work: A three-dimension usage perspective. International Journal of Information Management, 46, 83-92.

[51] Ali-Hassan, H., Nevo, D., \& Wade, M. (2015). Linking dimensions of social media use to job performance: The role of social capital. The Journal of Strategic Information Systems, 24(2), 65-89.

[52] Luqman, A., Cao, X., Ali, A., Masood, A., \& Yu, L. (2017). Empirical investigation of Facebook discontinues usage intentions based on SOR paradigm. Computers in Human Behavior, 70, 544-555.

[53] Punyanunt-Carter, N. M., Cruz, J. D. L., \& Wrench, J. S. (2018). Analyzing College Students' Social Media Communication Apprehension. Cyberpsychology, Behavior, and Social Networking, 21(8), 511-515.

[54] Orchard, L. J., \& Fullwood, C. (2010). Current perspectives on personality and Internet use. Social science computer review, 28(2), 155-169.

[55] Cao, F., \& Su, L. (2007). Internet addiction among Chinese adolescents: prevalence and psychological features. Child: care, health and development, 33(3), 275-281.

[56] Kuss, D. J., \& Griffiths, M. D. (2011). Online social networking and addiction-a review of the psychological literature. International journal of environmental research and public health, 8(9), 35283552.

[57] Chak, K., \& Leung, L. (2004). Shyness and locus of control as predictors of internet addiction and internet use. Cyberpsychology \& behavior, 7(5), 559-570.

[58] Ross, C., Orr, E. S., Sisic, M., Arseneault, J. M., Simmering, M. G., \& Orr, R. R. (2009). Personality and motivations associated with Facebook use. Computers in Human Behavior, 25(2), 578-586.

[59] Kuss, D. J., Van Rooij, A. J., Shorter, G. W., Griffiths, M. D., \& van de Mheen, D. (2013). Internet addiction in adolescents: 
Prevalence and risk factors. Computers in Human Behavior, 29(5), 1987-1996.

[60] Nitschke, J. B., Heller, W., Imig, J. C., McDonald, R. P., \& Miller, G. A. (2001). Distinguishing Dimensions of Anxiety and Depression. Cognitive Therapy and Research, 25(1), 1-22. doi:10.1023/A:1026485530405

[61] Schouten, R. W., Nadort, E., Harmse, V., Honig, A., van Ballegooijen, W., Broekman, B. F., \& Siegert, C. E. (2020). Symptom dimensions of anxiety and their association with mortality, hospitalization and quality of life in dialysis patients. Journal of psychosomatic research, 133, 109995.

[62] Mattick, R. P., \& Clarke, J. C. (1998). Development and validation of measures of social phobia scrutiny fear and social interaction anxiety. Behaviour research and therapy, 36(4), 455-470.

[63] Wheaton, M. G., Deacon, B. J., McGrath, P. B., Berman, N. C., \& Abramowitz, J. S. (2012). Dimensions of anxiety sensitivity in the anxiety disorders: Evaluation of the ASI-3. Journal of anxiety disorders, 26(3), 401-408.

[64] Rabner, J., Mian, N. D., Langer, D. A., Comer, J. S., \& Pincus, D. (2017). The relationship between worry and dimensions of anxiety symptoms in children and adolescents. Behavioural and cognitive psychotherapy, 45(2), 124.

[65] Barlow, D. H. (1985). The dimensions of anxiety disorders.

[66] Rector, N. A., Szacun-Shimizu, K., \& Leybman, M. (2007). Anxiety sensitivity within the anxiety disorders: Disorderspecific sensitivities and depression comorbidity. Behaviour research and therapy, 45(8), 1967-1975.

[67] Stöber, J. (2004). Dimensions of test anxiety: Relations to ways of coping with pre-exam anxiety and uncertainty. Anxiety, Stress \& Coping, 17(3), 213-226.

[68] Deacon, B., \& Abramowitz, J. (2006). Anxiety sensitivity and its dimensions across the anxiety disorders. Journal of anxiety disorders, 20(7), 837-857.

[69] Rodriguez, B. F., Bruce, S. E., Pagano, M. E., Spencer, M. A., \& Keller, M. B. (2004). Factor structure and stability of the Anxiety Sensitivity Index in a longitudinal study of anxiety disorder patients. Behaviour research and therapy, 42(1), 79-91.

[70] Chorpita, B. F. (2002). The tripartite model and dimensions of anxiety and depression: An examination of structure in a large school sample. Journal of abnormal child psychology, 30(2), 177-190.

[71] Masia-Warner, C., Storch, E. A., Pincus, D. B., Klein, R. G., Heimberg, R. G., \& Liebowitz, M. R. (2003). The Liebowitz social anxiety scale for children and adolescents: an initial psychometric investigation. Journal of the American Academy of Child \& Adolescent Psychiatry, 42(9), 1076-1084.

[72] Shear, M. K., Bjelland, I., Beesdo, K., Gloster, A. T., \& Wittchen, H. U. (2007). Supplementary dimensional assessment in anxiety disorders. International Journal of Methods in Psychiatric Research, 16(S1), S52-S64.

[73] Collimore, K. C., McCabe, R. E., Carleton, R. N., \& Asmundson, G. J. (2008). Media exposure and dimensions of anxiety sensitivity: Differential associations with PTSD symptom clusters. Journal of anxiety disorders, 22(6), 1021-1028.

[74] Lehrer, P. M., \& Woolfolk, R. L. (1982). Self-report assessment of anxiety: Somatic, cognitive, and behavioral modalities. Behavioral Assessment.

[75] Wenzel, A., Haugen, E. N., Jackson, L. C., \& Brendle, J. R. (2005). Anxiety symptoms and disorders at eight weeks postpartum. Journal of anxiety disorders, 19(3), 295311.

[76] Langford, W. S. (1937). Anxiety attacks in children. American Journal of Orthopsychiatry, 7(2), 210.

[77] Shin, L. M., \& Liberzon, I. (2010). The neurocircuitry of fear, stress, and anxiety disorders. Neuropsychopharmacology, 35(1), 169-191.

[78] McNaughton, N., \& Corr, P. J. (2004). A twodimensional neuropsychology of defense: fear/anxiety and defensive distance. Neuroscience \& Biobehavioral Reviews, 28(3), 285-305.

[79] Reiss, S. (1987). Theoretical perspectives on the fear of anxiety. Clinical Psychology Review, 7(6), 585-596.

[80] McWilliams, L. A., Stewart, S. H., \& MacPherson, P. S. (2000). Does the social concerns component of the Anxiety Sensitivity Index belong to the domain of anxiety sensitivity or the domain of negative evaluation sensitivity? Behaviour research and therapy, 38(10), 985-992.

[81] Gardenswartz, C. A., \& Craske, M. G. (2001). Prevention of panic disorder. Behavior Therapy, 32(4), 725-737.

[82] Lasser, K., Boyd, J. W., Woolhandler, S., Himmelstein, D. U., McCormick, D., \& Bor, D. H. (2000). Smoking and mental 
illness: a population-based prevalence study. Jama, 284(20), 2606-2610.

[83] Kashdan, T. B. (2004). The neglected relationship between social interaction anxiety and hedonic deficits: Differentiation from depressive symptoms. Journal of anxiety disorders, 18(5), 719-730.

[84] Tamir, M., Chiu, C.-Y., \& Gross, J. J. (2007). Business or pleasure? Utilitarian versus hedonic considerations in emotion regulation. Emotion, 7(3), 546.

[85] Shi, B., Li, S., Zhang, X., \& Zhang, D. (2017). Social-versus personal-oriented purchases: impacts of worry versus sadness on young consumers. Journal of Consumer Marketing.

[86] Arnold, M. J., \& Reynolds, K. E. (2012). Approach and avoidance motivation: investigating hedonic consumption in a retail setting. Journal of Retailing, 88(3), 399-411.

[87] Amedie, J. (2015). The impact of social media on society.

[88] Amichai-Hamburger, Y., \& Vinitzky, G. (2010). Social network use and personality. Computers in Human Behavior, 26(6), 1289-1295.

[89] Ormel, J., Riese, H., \& Rosmalen, J. G. (2012). Interpreting neuroticism scores across the adult life course: immutable or experiencedependent set points of negative affect? Clinical Psychology Review, 32(1), 71-79.

[90] Levine, P. A. (2002). Panic: Origins, insight, and treatment: North Atlantic Books.

[91] Stanton, A. L., \& Revenson, T. A. (2007). Adjustment to Chronic Disease: Progress and Promise in Research.

[92] Zeidner, M., \& Endler, N. S. (1995). Handbook of coping: Theory, research, applications (Vol. 195): John Wiley \& Sons.

[93] Borkovec, T. D. (2002). Life in the future versus life in the present. Clinical Psychology: Science and Practice, 9(1), 7680.

[94] Ohman, A. (1993). Fear and anxiety: Evolutionary, cognitive and clinical perspectives. Hand-book of Emotions, 511-536 